\title{
Seroprevalence of Avian Leukosis Virus Antigen Using ELISA Technique in Exotic Broilers and Nigerian Local Chickens in Zaria, Nigeria
}

\author{
N. A. Sani ${ }^{1^{*}}$, S. B. Oladele ${ }^{2}$ M. A. Raji ${ }^{2}$, and N. D. G. Ibrahim² \\ 1. Department of Veterinary Pathology, Faculty of Veterinary Medicine, University of \\ Abuja, Nigeria. 2. Department of Veterinary Pathology and Microbiology, Faculty of \\ Veterinary Medicine, ABU, Zaria, Nigeria \\ * Corresponding author E-mail:talk2nas2002@yahoo.com; Phone: +234-8032176723.
}

Received: 18-03-2011, Accepted: 12-04-2011, Published Online: 04-06-2011

\begin{abstract}
In an attempt to determine the seroprevalence of avian leukosis virus (ALV) in exotic broiler chickens and Nigerian local chickens in Zaria, Nigeria, a total of 600 sera (300 from exotic broiler chickens and 300 from Nigerian local chickens), obtained from the live bird market in Zaria, Nigeria, were tested for ALV p27 antigen by the antigen capture enzyme linked immunosorbent assay (ac-ELISA) technique. The age range of the Nigerian local chickens sampled in this study was 6-24 months, while that of the exotic broiler chickens used in this study was 2-3 months. Fourteen out of the 300 sera obtained from the exotic broiler chickens tested positive to ALV p27 antigen, which represents 4.70\%, while 180 of the 300 Nigerian local chicken sera were confirmed positive to the antigen, representing $60.00 \%$. Thirteen $(92.86 \%)$ of the fourteen sera from the exotic broiler chickens were lowly positive (ELISA Units range of $10-20 \%$ ) to ALV p27 antigen, while only one (7.14\%) serum sample was moderately positive to ALV p27 antigen with an ELISA Unit of $29.33 \%$. Of the 180 sera from the Nigerian local chickens that tested positive to ALV p27 antigen, $79(43.89 \%)$ were lowly positive with ELISA Units ranging from $10.67 \%$ to $21.33 \%$, while $101(56.11 \%)$ serum samples were moderately positive to ALV p27 antigen with ELISA Units ranging from $28.0 \%$ to $73.33 \%$. A higher seroprevalence of ALV was detected in Nigerian local chickens than the exotic broiler chickens.

Key words: Seroprevalence, Avian leukosis virus, ELISA, Zaria.
\end{abstract}

\section{I ntroduction}

The poultry sector in Nigeria, if properly harnessed has the potential of improving the nation's economy and improving the health status of the majorly poor populace, by providing affordable source of protein so as to meet the recommended daily intake of $0.8 \mathrm{~g} / \mathrm{kg}$ of protein (Shane and Neil, 2006). Disease has been identified as one of the most important factors that affect poultry production in Nigeria (Alabi et al., 2007). Avian leukosis is one of avian oncogenic diseases ravaging the poultry industry all over the world (Payne and Venugopal, 2000). Yet there is paucity of information on the disease status in the northern part of Nigeria where local chickens constitute the majority of poultry population (Majiyagbe and Lamorde, 1997).

Avian leukosis is caused by certain members of the leukosis/sarcoma group of avian retroviruses, commonly referred to as avian leukosis viruses (ALVs). They are classified into six (6) subgroups; A, $\mathrm{B}, \mathrm{C}, \mathrm{D}, \mathrm{E}$ and $\mathrm{J}$ (Kahn, 2005) based on the variation in their envelope glycoprotein, nucleotide sequence, virus-serum neutralization tests, virus interference, and host range (Payne and Fadly, 2003). Subgroups A, $\mathrm{B}, \mathrm{C}, \mathrm{D}$, and $\mathrm{J}$ are oncogenic and exogenous ALVs, while subgroup $\mathrm{E}$ is endogenous and regarded as having extremely low pathogenicity (Calnek et al., 1991). Avian leukosis virus subgroups A and B are most commonly associated with lymphoid leukosis and less commonly erythroid leukosis in layers, while ALV subgroup $\mathrm{J}$ is mainly associated with myeloid leukosis in broilers (Payne et al., 1991). In addition to causing tumours, ALV may induce immunosuppression and other production problems in affected flock (Arshad, 1998).

The clinical signs of AL are not pathognomonic (Davidson, 2004) and include in appetence, abnormal feathering, paleness of comb and wattles, loss of weight, decreased egg production, depression, paralysis and death (Abdel-Latif and Khalafalla, 2005). Avian leukosis virus is transmitted vertically from hen to chick through the egg and horizontally from bird to bird by direct or indirect contact (Cottral et al., 1954). 
The enzyme-linked immunosorbent assay (ELISA) is useful for the detection of ALV groupspecific antigen (p27) which is common to all of the subgroups. It is a sensitive, safe, rapid and easy to perform diagnostic tool (Smith et al., 1979). The ALV ELISA diagnostic method is reported to have a $99.2 \%$ sensitivity and $100 \%$ specificity, and can be used clinically for screening purpose (Pham et al., 1999; Silva et al., 2007). Although evidences have shown that some lesions which mimic AL have been observed in birds in Zaria, the disease is yet to be confirmed by highly sensitive and specific diagnostic methods. Therefore this study has become necessary to ascertain the status of ALV antigen in chickens in Zaria, Northern Nigeria. To the best of our knowledge, this is the first report on the prevalence of avian leukosis virus in Zaria, Northern Nigeria.

\section{Materials and Methods}

Study area: The study was carried out in Zaria, Kaduna State, located in the Northern Guinea Savannah Zone of Nigeria, between latitude $7^{\circ} \mathrm{N}$ and $11^{\circ} \mathrm{N}$, and longitude $7^{\circ}$ and $44^{\circ} \mathrm{E}$. The average annual rainfall ranges from 1000 to $1250 \mathrm{~mm}$ with temperatures ranging from $17^{\circ} \mathrm{C}$ to $33^{\circ} \mathrm{C}$ (Saidu et al., 1994).

Experimental birds: The Nigerian local chickens vary greatly in phenotypic characteristics such as size, conformation, and plumage color. They are generally hardy, adapted to harsh management and environmental factors, with little or no veterinary inputs as compared to the exotic breeds of chickens.

A total of 600 sera samples were used in this study. Three hundred Nigerian local chickens (6 - 24 months old) and 300 exotic broiler chickens (2 - 3 months old), obtained from Sabon-gari live-bird market, Zaria, were sampled, using simple random sampling technique.

Blood sampling and serology: Three milliliters of blood was obtained from each bird, dispensed into a separate test tube and transported on ice packs to the Chemical Pathology Laboratory, Ahmadu Bello University Teaching Hospital (ABUTH), Shika, where the serological test (ELISA) was performed. The blood was allowed to stand for one (1) hour to allow the blood to clot. The blood was then centrifuged at $1,000 \mathrm{~g}$ for 10 minutes (WOAH, 2008) so as to clearly separate the serum from the blood. The sera were dispensed into serum tubes and stored frozen at $20^{\circ} \mathrm{C}$ until used. Test tubes and serum tubes were labeled appropriately using indelible marking pen.

Enzyme linked immuno-sorbent assay: The sera were tested using colorimetric sandwich ELISA for the presence of ALV group specific antigen (p27) as described by the manufacturer (Affini-Tech LTD, USA). The ELISA was carried out at the Chemical Pathology Laboratory, ABUTH.

The intensity of the colour produced from the ELISA test was measured photometrically at 405410nm using ELISA reader. The ELISA units (EUs) for all samples tested on the Affini Tech ALV Antigen Detection Test Kit was calculated using the formula below:

Average Absorbance (Test sample)-Average Absorbance (Negative)/Average Absorbance(Positive)-Average Absorbance (Negative) $\times 100=$ ELISA Unit

The Positive Control value was set at 100 ELISA Unit(EU).

The ELISA unit values obtained were interpreted as recommended by the manufacturer. Enzyme-linked immunosorbent assay units less than 10 were considered negative while EUs greater than 10 were considered positive for ALV p27 antigen. Elisa Units (EUs) 10-25 were considered weakly positive, EUs 25-75 were considered moderately positive, while EUs greater than 75 were considered as strongly positive for ALV P27 antigen.

\section{Results}

In this study, a total of 600 sera (three hundred from local chickens and three hundred from broilers) were tested for ALV p27 antigen by ELISA technique. Fourteen out of the 300 sera obtained from exotic broilers tested positive to ALV p27 antigen which represents $4.70 \%$, while 180 of the 300 sera from Nigerian local chickens were confirmed positive to the antigen, representing $60.00 \%$. Thirteen $(92.86 \%)$ of the fourteen sera from exotic broiler chickens were lowly positive (EUs range of 10-20\%) to ALV p27 antigen, while one $(7.14 \%)$ serum sample was moderately positive to ALV p27 antigen, with an EU of $29.33 \%$. Of the 180 sera from Nigerian local chickens that tested positive to ALV p27 antigen, 79 (43.89\%) were lowly positive, with EUs ranging from $10.67 \%$ to $21.33 \%$, while $101(56.11 \%)$ serum samples were moderately positive to ALV p27 antigen, with EUs ranging from $28.0 \%$ to $73.33 \%$.

\section{Discussion}

Avian leukosis has been reported worldwide to be a major cause of serious economic losses to the poultry industry. Negative impact of the disease on chickens include reduced growth, unevenness of growth rates within flocks, and a greater susceptibility to developing serious disease when challenged by 
immunosuppressive viruses or secondary bacterial invaders (Bagust et al., 2004). Decreased egg production, decreased egg weight and shell thickness as well as fertility, hatchability and liveability problems have also been observed (Gavora et al., 1980; Gavora et al., 1982). These production problems, which are attributable to ALV infection, are common occurrences in the poultry industry in Nigeria.

Results of this study showed a prevalence of $4.70 \%(14 / 300)$ in exotic broiler chickens which agrees with the findings of other workers who also got low prevalence rates such as $1.25 \%$ by Olabode $e t$ al. (2009), less than $5 \%$ by Owoade et al. (2006), and $3.33 \%$ by Mohammadi et al.(2008). A prevalence of $60.0 \%(180 / 300)$ in Nigerian local chickens was recorded in this study which agrees with the finding of Emikpe et al. (2007), who reported a high prevalence of $70.7 \%$, and Mohammadi et al. (2008), who also reported a prevalence rate as high as $76 \%$. The higher prevalence rate in Nigerian local chickens as compared with that of the exotic broiler chickens in this study can be attributed to the free range management system of the Nigerian local chickens which expose them more to infectious agents than the exotic broiler chickens which are raised under intensive system of management. Also, the older Nigerian local chickens (6-24 months old) sampled in this study, probably had more exposure time to these infectious agents than the broiler chickens that were just $2-3$ months old as at the time of sampling. It was therefore not surprising that only one $(7.14 \%)$ out of the 14 positive sera from the exotic broiler chickens sera was moderately positive to 27 ALV antigen, with an EU of $29.33 \%$, while the remaining $13(92.86 \%)$ positive sera were lowly positive to 27 ALV antigen, with EUs ranging from 10- 20\%. This is in contrast with the results of the Nigerian local chickens which showed that only 79 (43.39\%) of the 180 were lowly positive to the p27 ALV antigen, with EUs ranging from $10.67 \%$ to $21.33 \%$, while $101(56.11 \%)$ sera were tested to be moderately positive to the p27 ALV antigen, with EUs ranging from $28.0 \%$ to $73.33 \%$. The discrepancy in age between these groups of chickens is probably the reason why higher levels of ALV infection was found in the Nigerian local chickens when compared to the exotic broilers. It could therefore be deduced from this study that there is a greater chance of detecting ALV antigen in older birds than in younger birds.

The high level of ALV infection in Nigerian local chickens, as seen in this study, could make effective control and eradication of avian leukosis difficult to achieve in commercial poultry. This is because the Nigerian local chickens could serve as source of contamination of the environment and spread of ALV. Strict adherence to biosecurity on farms could be beneficial in limiting the spread of these group of viruses from infected poultry farms to uninfected farms. Screening of breeder chickens for ALV and removal of chickens found to be viraemic, may also help in controlling the spread of ALV from dam to chicks as the virus is known to be transmitted vertically. Also, efforts should be channeled into developing vaccines that will protect birds against the effect of this important group of retroviruses of chickens.

\section{Acknowledgements}

We are grateful to God for seeing us through this work. To Dr Tenuche Oremeyi for her moral support, and to Affini-Tech Limited, USA for donating the ELISA kit used in this study.

\section{References}

1. Abdel-Latif, M. M. and Khalafalla, A. I. (2005). Detection by PCR of multiple subgroups of avian leukosis virus in broilers in the Sudan. Journal of Animal and Veterinary Advances, 4(3): 407-413.

2. Alabi, R. A., Esobhawan, A. O. and Aruna, M. B. (2007). Econometric determination of contribution of family poultry to women's income in Niger-Delta, Nigeria. Journal of Central European Agriculture, 2(4): 753-760.

3. Arshad, S. S. (1998). Avian leukosis virus subgroup J: Disease and Diagnosis. Proceedings of $21^{\text {st }}$ symposium of the Malaysian Society for Microbiology, Seri Kembangan, Selangor. Pp. 5-9.

4. Bagust, T., Fenton, S. and Reddy, M. (2004). Avian leukosis virus sub-group $\mathrm{J}$ (ALV-J): Developing laboratory technologies for diagnosis in Australia. Rural Industries Research and Development Corporation, Publication No 04/116

5. Calnek, B.W., Barnes, H.J., Beard, C.W., Reid, W.M. and Yoder, H.W. (1991). Diseases of Poultry, 10th edition. Iowa State University Press, Ames, IA. pp. 367-368.

6. Cottral, G. E., Burmester, B. R. and Waters, N. F. (1954). Egg transmission of avian lymphomatosis. Poultry Science, 33: 1174-1184

7. Davidson, I. (2004). Differential diagnosis of avian oncogenic viruses. http://www.poultrymed.com/files/ Oncogenic. accessed on 08/02/2010 at 11:14 PM.

8. Emikpe, B. O., Oladele, O. A., Oluwayelu, D. O., Adene, D. F., Ohore, O. G. and Bolarinwa, A. B. (2007). Detection of avian leukosis virus P27 antigen in Nigeria indigenous chicken. Journal of Animal and Veterinary Advances, 6(1): 36-38.

9. Gavora, J. S., Spencer J. L. and Chambers, J. (1982). Performance of meat-type chickens test-positive and -negative for lymphoid leukosis virus infection. Avian Pathology, 11:29-38.

10. Gavora, J. S., Spencer, J. L., Gowe, R. S. and Harris, D. L. (1980). Lymphoid leukosis virus infection: effects on production and mortality and consequences in selection for high egg production. Poultry Science, 59:2165-78. 
11. Kahn, C. M. (2005). Leukosis/sarcoma group. In: the Merck Veterinary Manual, $9^{\text {th }}$ Edition. Published by Merck and Co., INC. USA. Pp. 2251.

12. Michael, T. (1995). Estimation of disease prevalence. In: Veterinary Epidemiology, $2^{\text {nd }}$ Edition. Published by Blackwell Science Limited, pp. 183.

13. Majiyagbe, K. A. and Lamorde, A. G. (1997). Nationa coordinated research programme on livestock diseases: subsectoral goals, performance and medium-term research plan. Tropical Veterinarian, 15: 75-83.

14. Mohammadi, A., et.al. (2008). Detection of avian leukosis virus (ALV) in albumen of Shiraz commercial and local layer flocks using ELISA and RT-PCR. Iranian Journal of Veterinary Research, 9(3): 24.

15. Olabode, H. O. K., et. al. (2009). Prevalence of avian leukosis and Marek's disease in Ilorin, Kwara State, Nigeria Nigerian Veterinary Journal, 30(3): 64-68.

16. Owoade, A. A., Ducatez, M. F. and Muller, CP. (2006). Seroprevalence of Avian Influenza Virus, Infectious Bronchitis Virus, Reovirus, Avian Pneumovirus, Infectious Laryngotracheitis Virus, and Avian Leukosis Virus in Nigerian Poultry. Avian Diseases, 50: 222-227.

17. Payne, L. N. and Fadly, A. M. (2003). Leukosis/sarcoma Group. In: Diseases of Poultry. $11^{\text {th }}$ Edition. Calneck, B. W., Barnees, H. J., Beard, C. W., McDougald, C. R. and Saif, Y. $\mathrm{X}$. (Editors). Iowa State University Press, Ames, Iowa. Pp. 465-519.

18. Payne, L. N. and Venugopal, K. (2000). Neoplastic diseases:
Marek's disease, avian leukosis and reticuloendotheliosis. Review Science Technical, Office of International Epizootics, 19: 544-564.

19. Payne, L. N., et.al. (1991). A novel subgroup of exogenous avian leukosis virus in chickens. Journal of General Virology, 72(4):801-807.

20. Pham, T.D., Spencer, J.L. and Johnson, E.S. (1999). Detection of avian leukosis virus in albumen of chicken eggs using reverse transcription polymerase chain reaction. Journal of Virology Methods, 78: 1-11.

21. Saidu, L., Abdu, P. A., Umoh, J. U. and Abdullahi, U. S. (1994). Disease of indigenous chicken. Bulletin Animal Health Production in Africa, 42: 19-23.

22. Shane, B. and Neil, M. (2006). A review of issues of dietary protein intake in humans. International Journal of Sport Nutrition and Exercise Metabolism, 16: 2.

23. Silva, R.F., Fadly, A.M. and Taylor, S.P. (2007). Development of a polymerase chain reaction to differentiate avian leukosis virus (ALV) subgroups: Detection of an ALV contaminant in commercial Marek's disease vaccines. Avian Diseases, 51: 663-667.

24. Smith, E. J., Fadly, A. M. and Okazaki, W. (1979). An enzyme-linked immunosorbent assay for detecting avian leukosis-sarcoma viruses. Avian Diseases, 23: 698-707.

25. World Organization for Animal Health (2008). Collection and shipment of diagnostic specimen.http://www.oie.int/ eng/normes/manual/2008/pdf/1.1.01_collection.pdf Accessed 25/01/2010 at 09:24 